\title{
Measurement of power and energy consumption of a competition-mobile-robot
}

\author{
Tsing-Tshih Tsung ${ }^{1, a}$, Yun-Ju Chuang ${ }^{2, b}$, Ho Chang ${ }^{2}$, Chun-Lun Shen ${ }^{3}$ and Yin-Tung Sun ${ }^{2}$ \\ ${ }^{1}$ Department of Mechanical Engineering, Chinese Culture University, Taipei, Taiwan. \\ ${ }^{2}$ Graduate Institute of Manufacturing Technology, National Taipei University of Technology, Taipei, Taiwan. \\ ${ }^{3}$ Institute of Mechatronic Engineering, National Taipei University of Technology, Taipei, Taiwan.
}

\begin{abstract}
Power and energy consumption are the two most important factors for successful operation; they also play important roles in performance identification.The measurement of power and energy consumption is a common test in the development process of a competition mobile robot. If the power of a competition mobile robot is not sufficient, the running time in the competition will be too long and winning the competition will not be possible. Thus, the power and energy consumption are basic and important measurement parameters for a competition mobile robot. In this paper, five types of hand-made competition mobile robots are successfully developed and their performances are measured. From the measurements, their powers and energy consumptions are evaluated and analyzed, respectively. The test results show large differences in the powers and energy consumptions of the five models, even though the same motors were used. The design and construction of the competition mobile robot are the key parameters that cause these huge differences. It is possible to develop the measurement techniques for power and energy consumption, quickly and precisely, to determine how to modify a competition mobile robot rapidly and efficiently to a condition optimal for a mobile robot competition.
\end{abstract}

\section{Introduction}

Robots can perform a large number of tasks for humans, using the different kinds of energy available today; therefore, there are many different types of robots, and many more will be developed in the future.

For the training and education of the mobile robots, many countries hold Robotics Competitions such as World Skills - Mobile Robotics, IEEE International Robot Hands on Competition and Symposium, and RoboCup as shown in figure.1

For a competition mobile robot, power and energy consumption are always the key factors in the competition. The power and energy consumption of a competition mobile robot play important roles in deciding the results of performance identification in a mobile robot competition.

In a robot competition, energy and time are key factors that decide the performance identification. For a mobile competition robot, many kinds of energies can be chosen, and many different types of

\footnotetext{
${ }^{\mathrm{a}}$ Corresponding author : tttsung@gmail.com

${ }^{\mathrm{b}}$ Corresponding author : andy2551468@gmail.com
} 
power units can be used. The weight of the power unit that the robot can carry is limited in the competitions; moreover, the competition time is also limited. Therefore, in order to win the competition, the robot must be simple, fast, and must have low energy consumption.

Measurement of power is a common performance identification technique in a mobile robot competition. If the power of a competition mobile robot is not enough, the competition time will be too long and it will not be possible to win the competition. Thus, the measurements of power and energy consumption are the basic measurements for a competition mobile robot, and their results will be presented in this paper.

In the present study, five types of electricity as energy sources for the robots were produced. measured energy five robots working in individual consumption, energy and time analysis of different robots in each work.

The The measurement results of the final energy consumption and the amount of time, can be used in the robot competition for creating a robot arrangement conducive to the competition tasks, in order to benefit the ultimate task, which is winning the race.

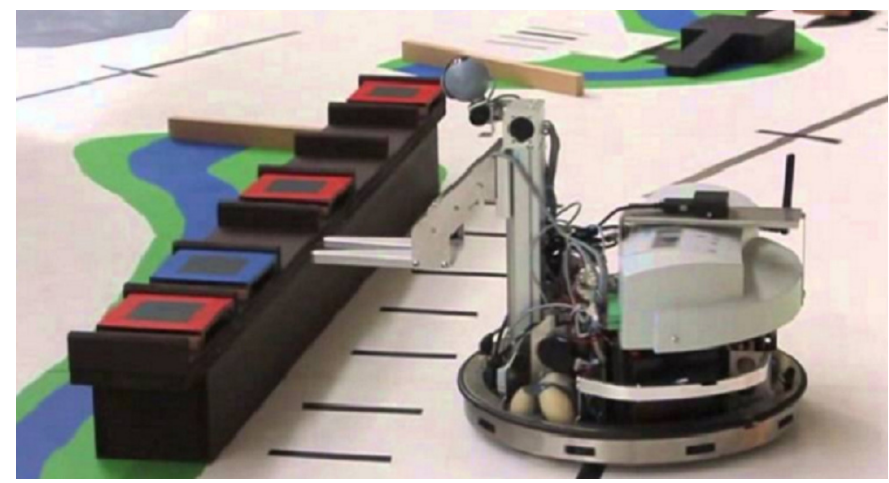

Figure 1. Robotics Competitions

\section{Types of Competition Mobile Robots}

Five types of the competition robots were developed in this research. The power and energy consumption of each were measured and analyzed. The energy consumptions of each working process in the competition robots, and the operating times for the various durations of the various processes, were measured and analyzed in detail. Furthermore, their performances were identified. According to the performance identification result, the energy distribution mode will be determined and the control unit will be built.

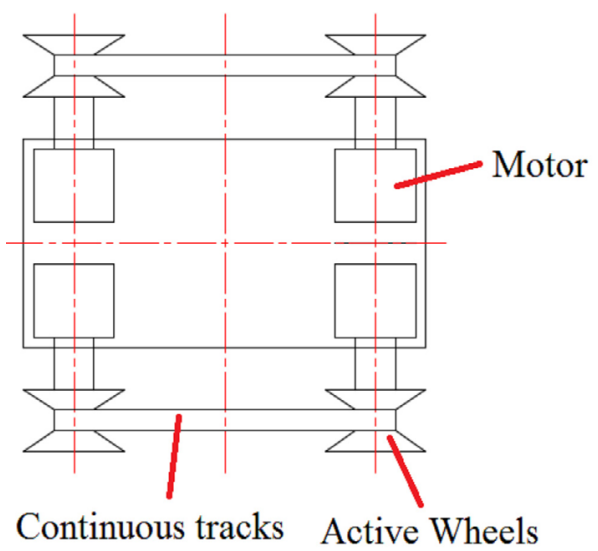

Figure 2. Sketch of Type-1 robots 


\subsection{Type-1 robot}

Figure 2 shown the Type- 1 robot has two continuous tracks, four active wheels, four motors, and a weight of $1.6 \mathrm{~kg}$.The continuous track design can increase the friction while climbing the ramp.

\subsection{Type-2 robot}

Figure 3 shown the Type-2 robot has two continuous tracks, four active wheels, two idler wheels, four motors, and a weight of $1.5 \mathrm{~kg}$.The idler-wheel design can adjust the elastic in the continuous tracks so that they work more smoothly.

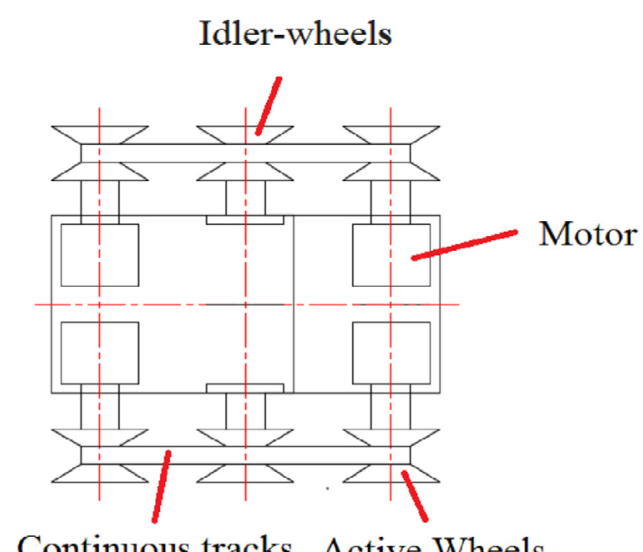

Continuous tracks Active Wheels

Figure 3. Sketch of Type-2 robots

\subsection{Type-3 robot}

Figure 4 shown the Type- 3 robot has four active wheels, four motors, and a weight of $1.15 \mathrm{~kg}$. The non-continuous track design can improve the speed.

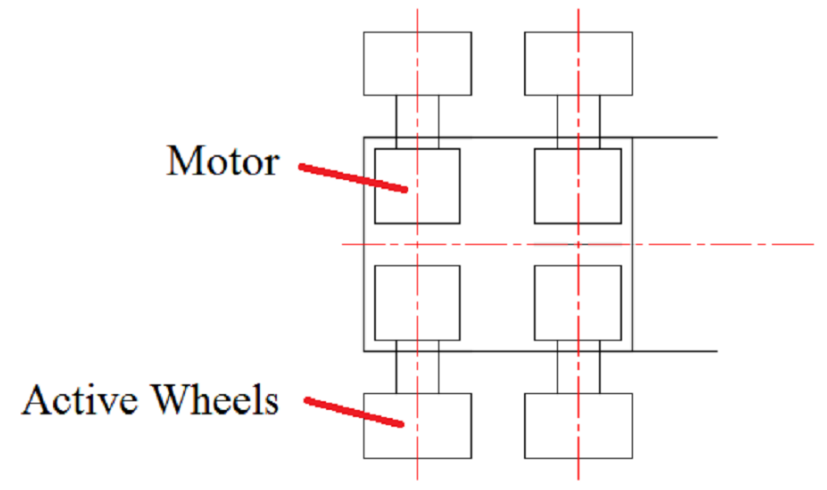

Figure 4. Sketch of Type-3 robots

\subsection{Type-4 robot}

Figure 5 shown the Type- 4 robot has two active wheels, two passive wheels, two motors, and a weight of $3.7 \mathrm{~kg}$. The cutting two-motor design will change the center of rotation, and the distance in between will affect the rotation. 


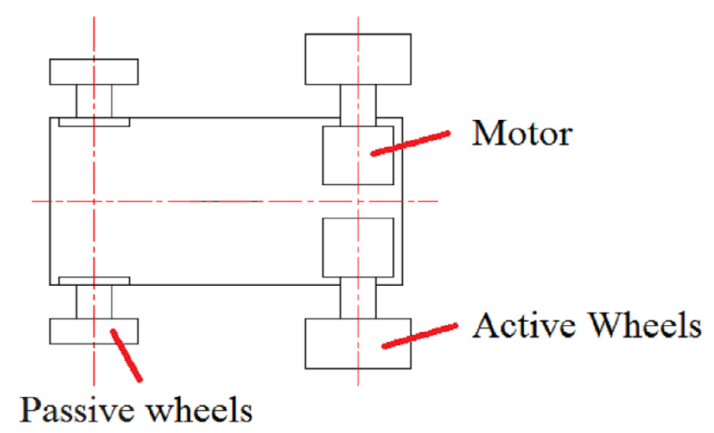

Figure 5. Sketch of Type-4 robots

\subsection{Type-5 robot}

Figure 6 shown the Type-5 robot has two active wheels, one passive wheel, two motors, and a weight of $4.2 \mathrm{~kg}$. The single passive wheel enables a smoother rotation.

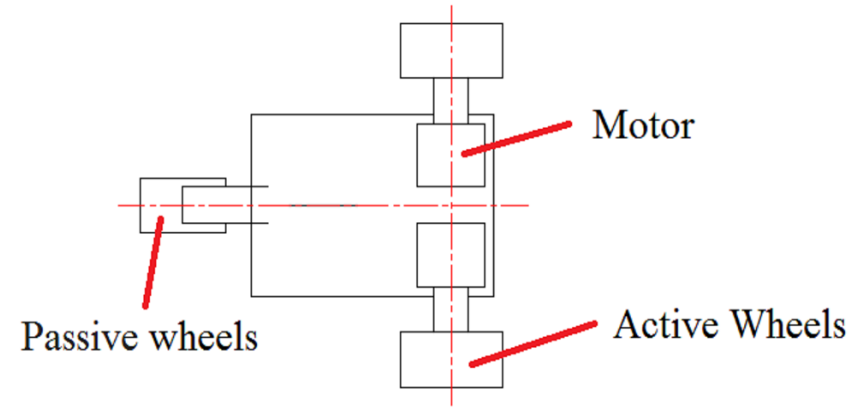

Figure 6. Sketch of Type-5 robots

\section{Battery performance characteristics}

Table 1 and Figure 7 show the performance of the battery. This battery used is of 12-V, 2.3-Ah capacity.

Table 1. Battery performance (YUASA, 2006)

\begin{tabular}{l|c|} 
& NP2.3.12 \\
\hline Nominal Capacity (Ah) & 2.3 \\
\hline 20hr to $1.75 \mathrm{vpc} 30^{\circ} \mathrm{C}$ & 12 \\
\hline Voltage & 76 \\
\hline Energy Density (Wh.L.20ht) & 29 \\
\hline Specific Energy (Wh.kg.20hr) & 65 \\
\hline Int. Resistance (m.Ohms) & 23 \\
\hline Maximum discharge (A) & 69 \\
\hline Short Circuit current (A) &
\end{tabular}




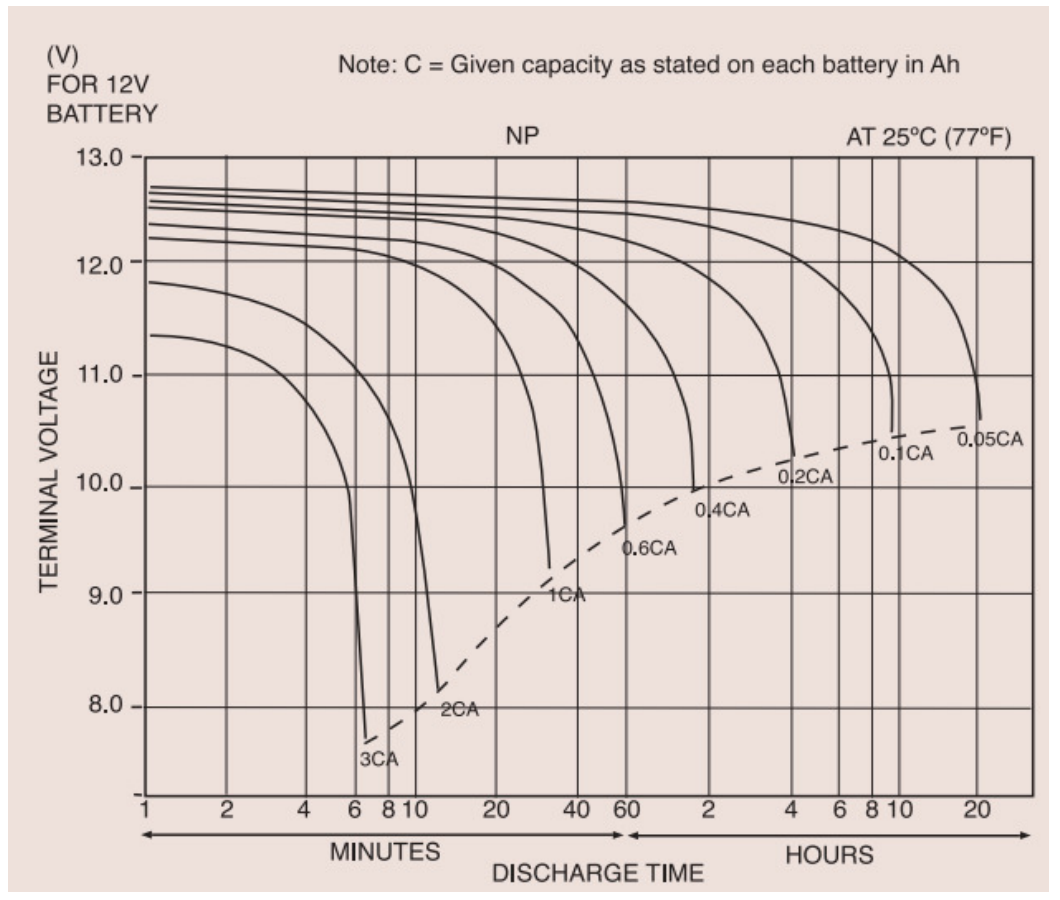

Figure 7. Battery performance (YUASA, 2006)

\section{Test setup for competition mobile robot}

The testing setup is based on the setup used in the World Skills Manufacturing Team Challenge, 2013 as shown in figure 8. It involves the task of climbing a ramp.

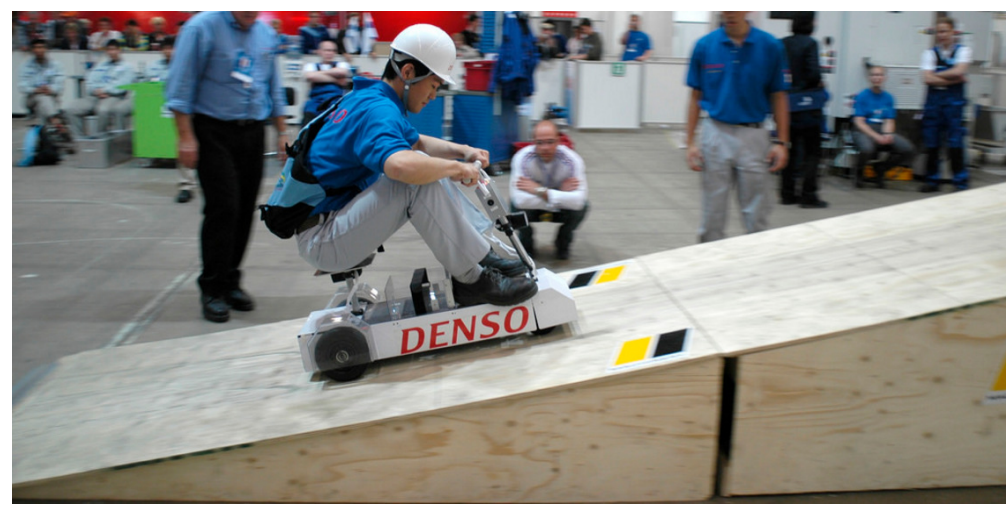

Figure 8. World Skills Manufacturing Team Challenge, 2013

This research measures the power and energy consumption of a competition mobile robot climbing a slope.

The testing setup is shown in Figure 9.

The research follows these steps for testing:

1. Measure the voltage at START.

2. Measure the voltage at END.

This test will measure the power and energy consumption of a competition mobile robot. 


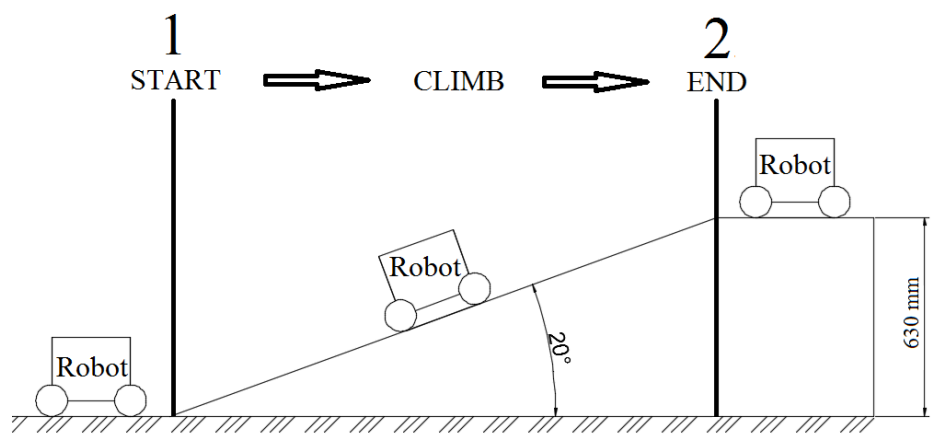

Figure 9. Ramp testing setup

\section{Results and discussion}

\subsection{Type-1 robot}

The results from the Type-1 robot are shown in Figures 10 to 12.

Figure 10 shown the numbers 1 to 10 energy consumption in the 0.05 to $0.1 \mathrm{~V}$.

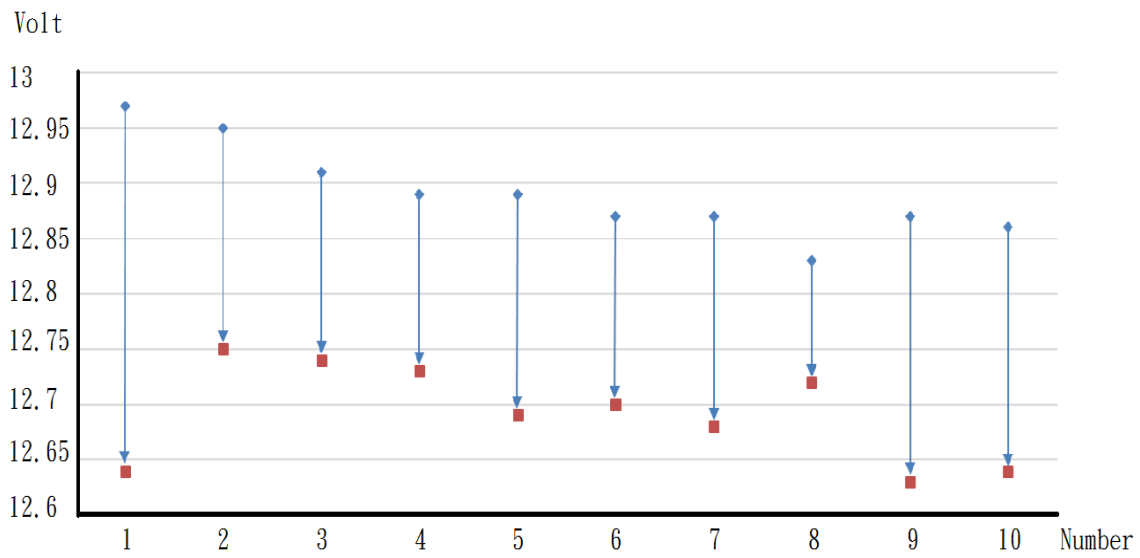

Figure 10. Energy consumption of Type-1 robot

Figure 11 shown the numbers 1 to 10 battery's voltage recovery in 0 to $0.08 \mathrm{~V}$.

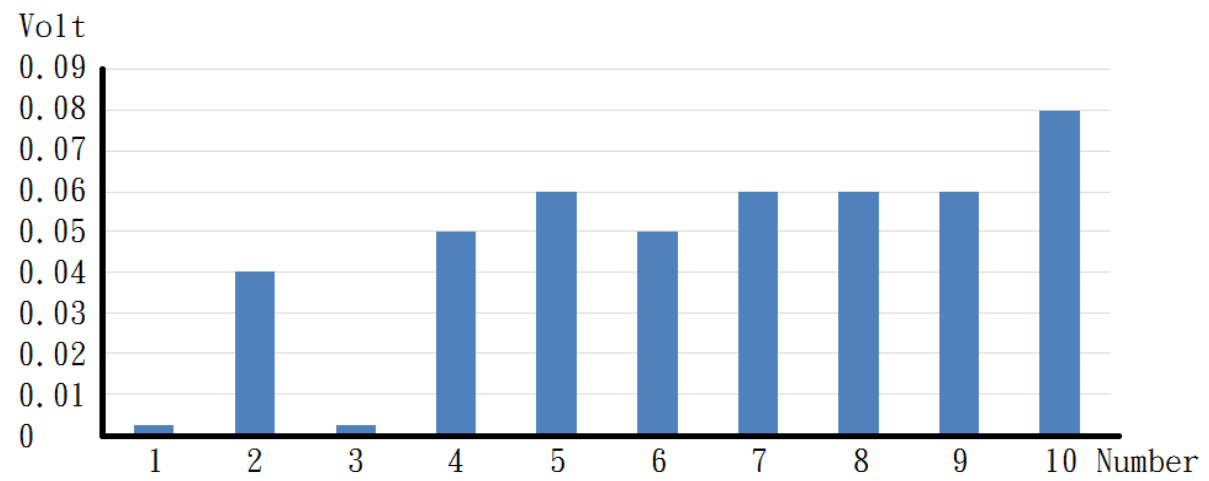

Figure 11. Battery's Volt recover of Type-1 robot 
Figure 12 shown the numbers 1 to 10 power in 0.6 to $1.3 \mathrm{~W}$.

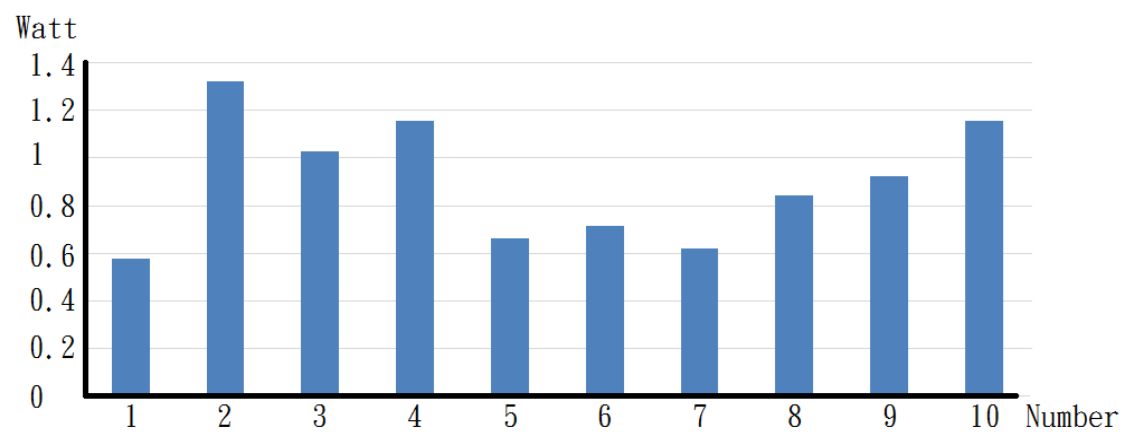

Figure 12. Power of Type-1 robots

\subsection{Type-2 robot}

The results from the Type- 2 robot are shown in Figures 13 to 15.

Figure 13 shown the numbers 1 to 10 energy consumption in the 0.11 to $0.33 \mathrm{~V}$.

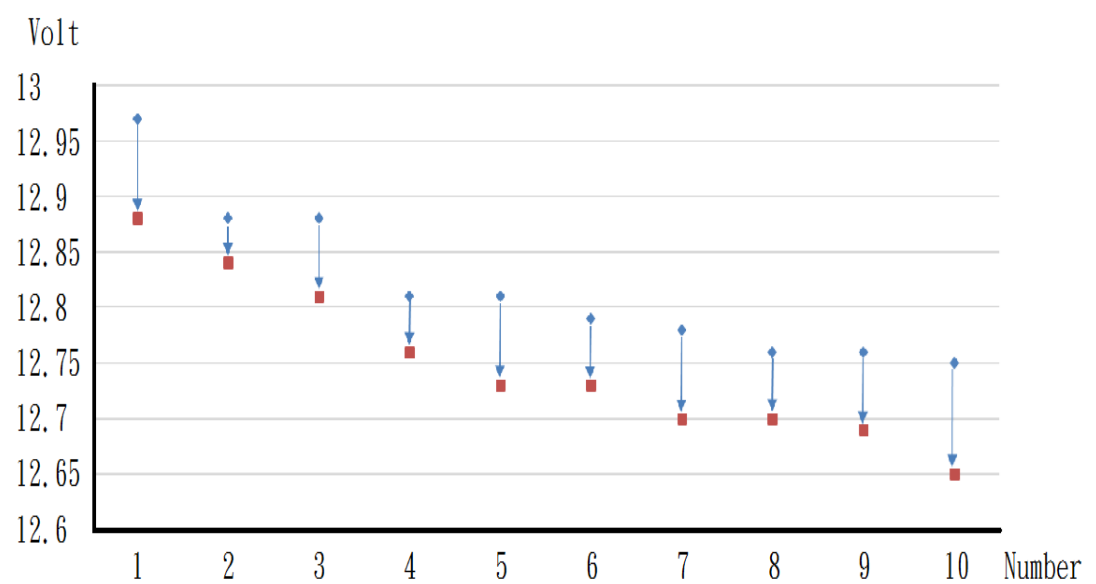

Figure 13. Energy consumption of Type-2 robot

Figure 14 shown the numbers 1 to 10 Battery's Volt recover in 0.15 to $0.31 \mathrm{~V}$.

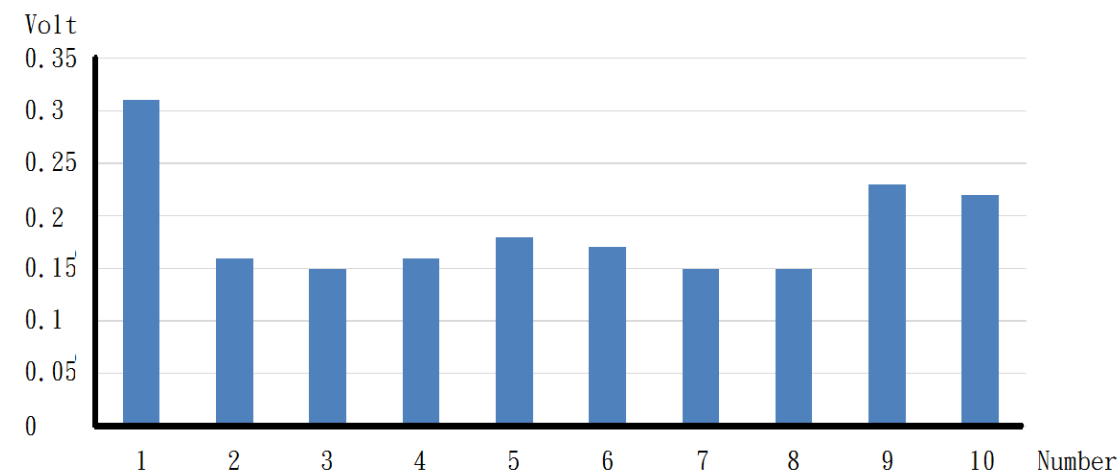

Figure 14. Battery's Volt recover of Type-2 robot

Figure 15 shown the numbers 1 to 10 Power in 0.28 to $0.47 \mathrm{~W}$. 


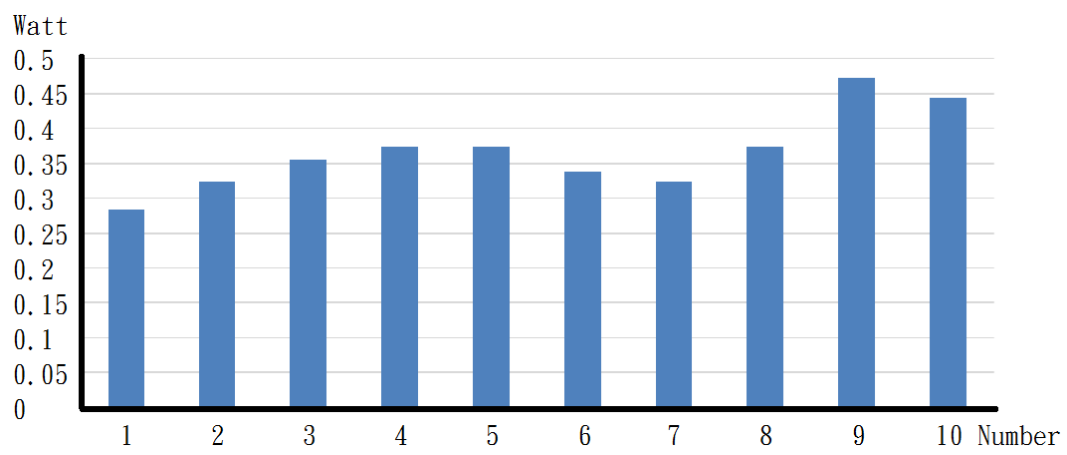

Figure 15. Power of Type-2 robots

\subsection{Type-3 robot}

The results from the Type-3 robot are shown in Figures 16 to 18.

Figure 16 shown the numbers 1 to 10 energy consumption in the 0.12 to $0.16 \mathrm{~V}$.

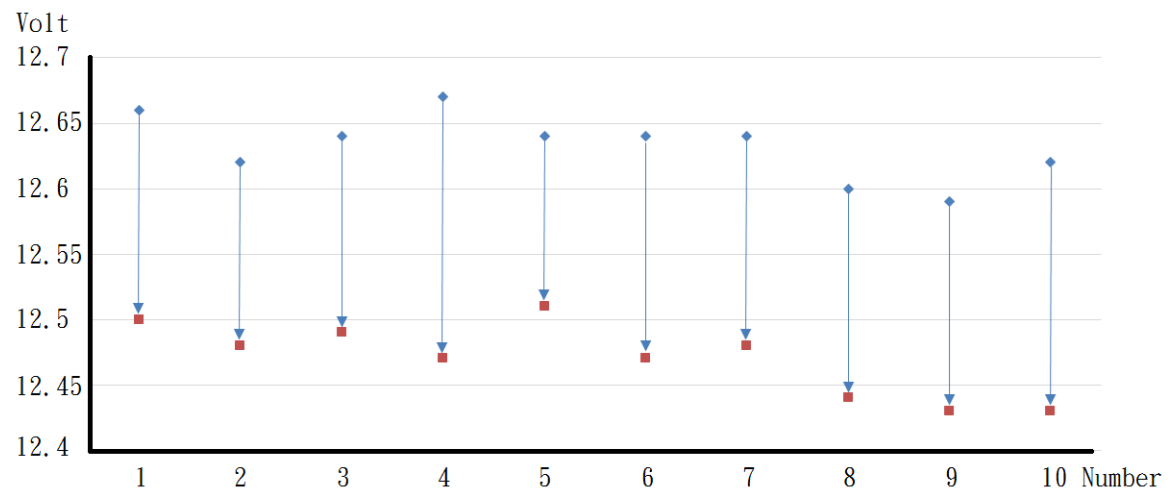

Figure 16. Energy consumption of Type-3 robot

Figure 17 shown the numbers 1 to 10 Battery's Volt recover in 0.12 to $0.2 \mathrm{~V}$.

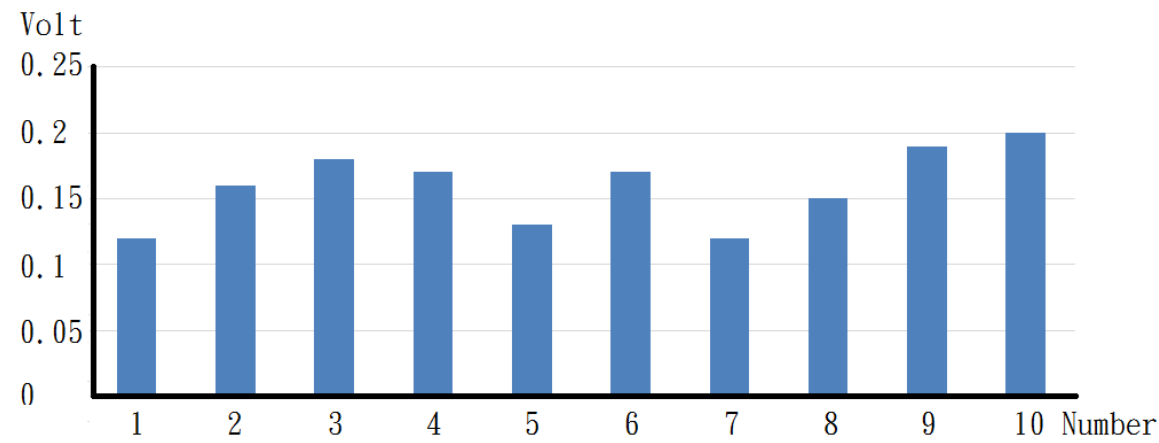

Figure 17. Battery's Volt recover of Type-3 robot

Figure 18 shown the numbers 1 to 10 Power in 0.4 to $0.69 \mathrm{~W}$. 


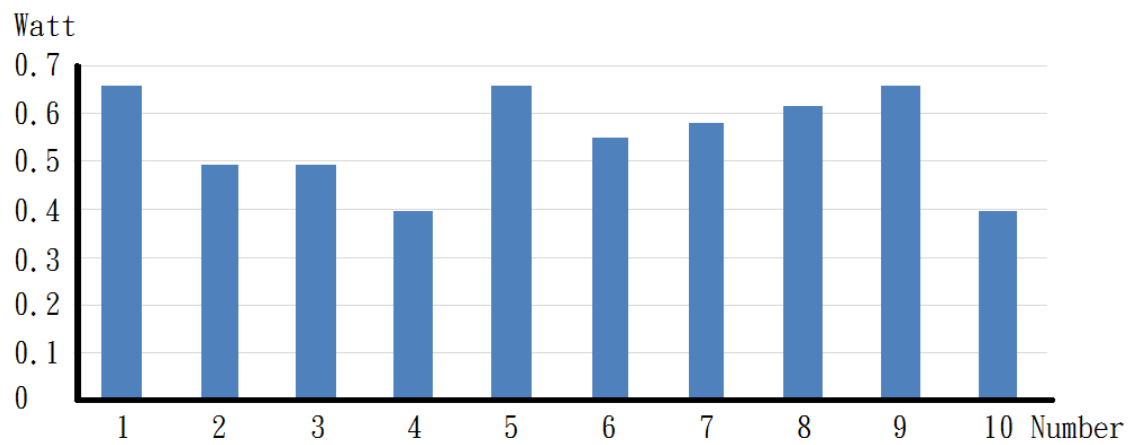

Figure 18. Power of Type- 3 robots

\subsection{Type-4 robot}

The results from the Type-4 robot are shown in Figures 19 to 21.

Figure 19 shown the numbers 1 to 10 energy consumption in the 0.08 to $0.17 \mathrm{~V}$.

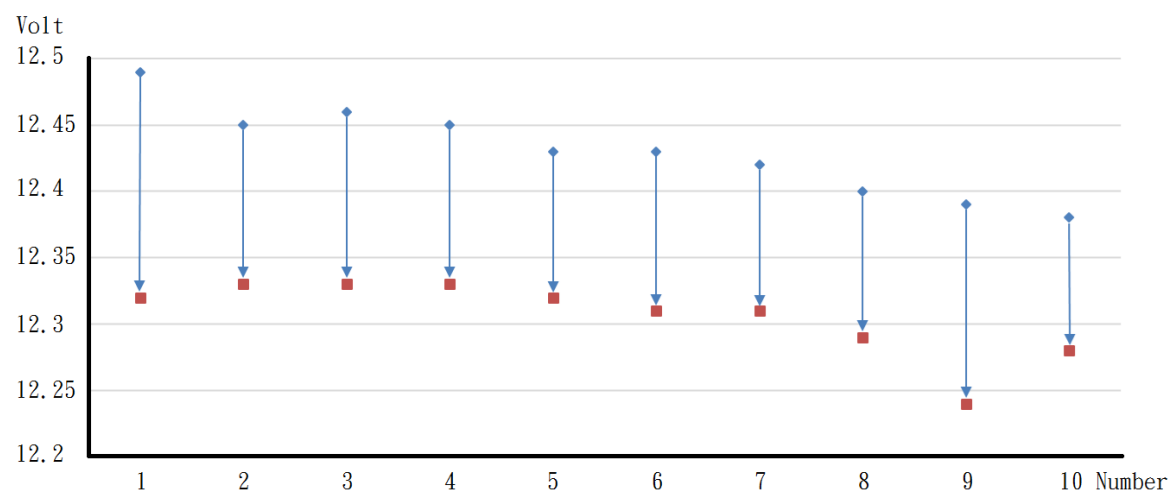

Figure 19. Energy consumption of Type-4 robot

Figure 20 shown the numbers 1 to 10 Battery's Volt recover in 0.09 to $0.26 \mathrm{~V}$.

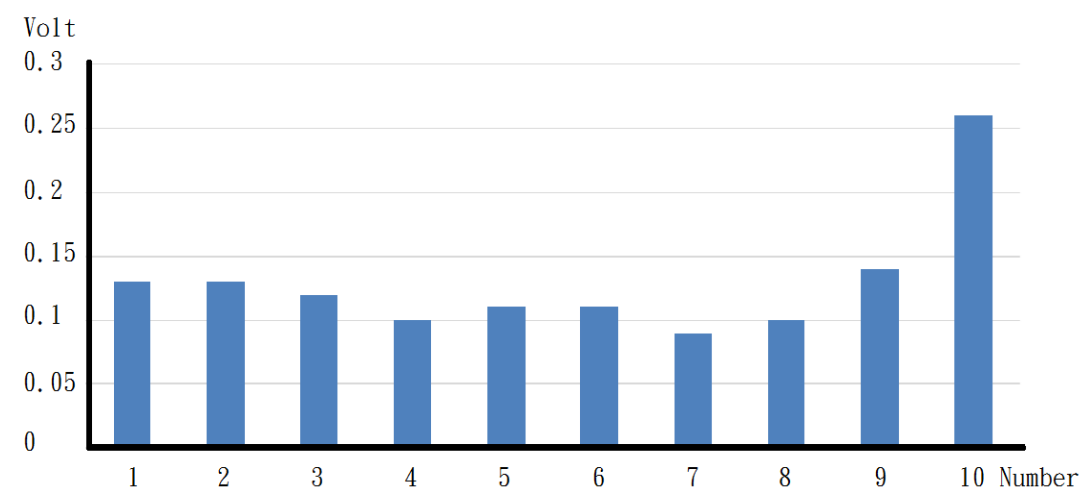

Figure 20. Battery's Volt recover of Type-4 robot

Figure 21 shown the numbers 1 to 10 Power in 1.14 to $1.76 \mathrm{~W}$. 


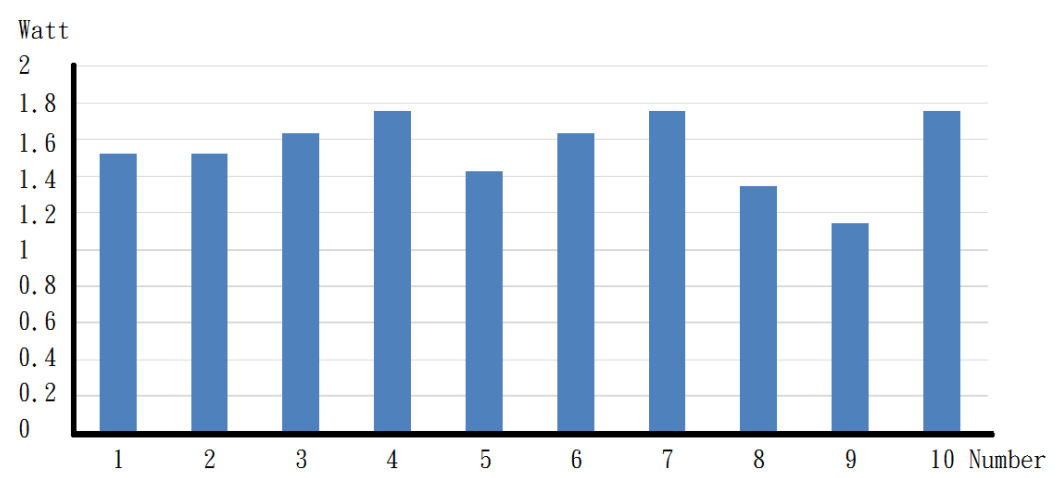

Figure 21. Power of Type-4 robots

\subsection{Type-5 robot}

The results from the Type-5 robot are shown in Figures 22 to 24.

Figure 22 shown the numbers 1 to 10 energy consumption in the 0.06 to $0.14 \mathrm{~V}$.

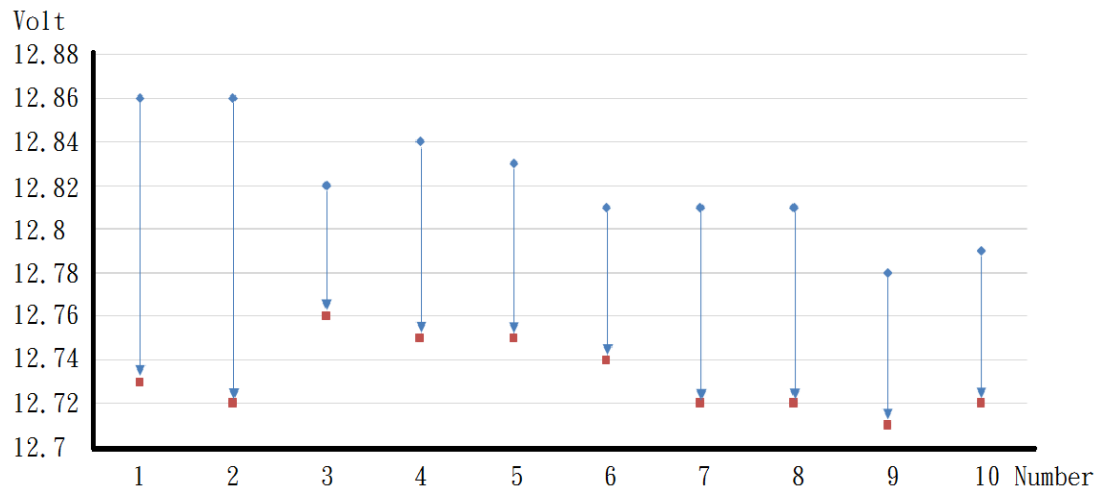

Figure 22. Energy consumption of Type-5 robot

Figure 23 shown the numbers 1 to 10 Battery's Volt recover in 0.06 to $0.13 \mathrm{~V}$.

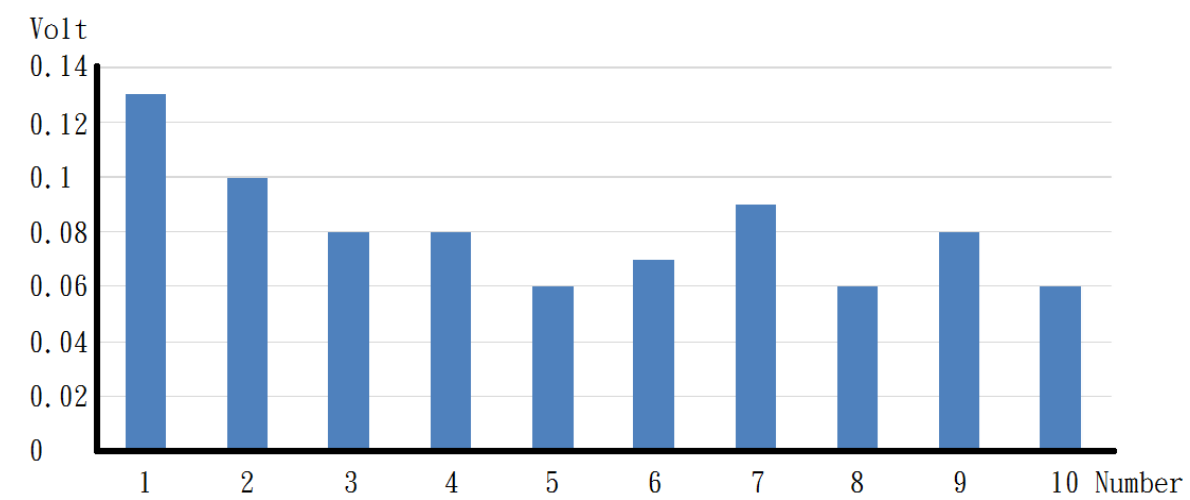

Figure 23. Battery's Volt recover of Type-5 robot

Figure 24 shown the numbers 1 to 10 Power in 1.73 to $3.7 \mathrm{~W}$. 


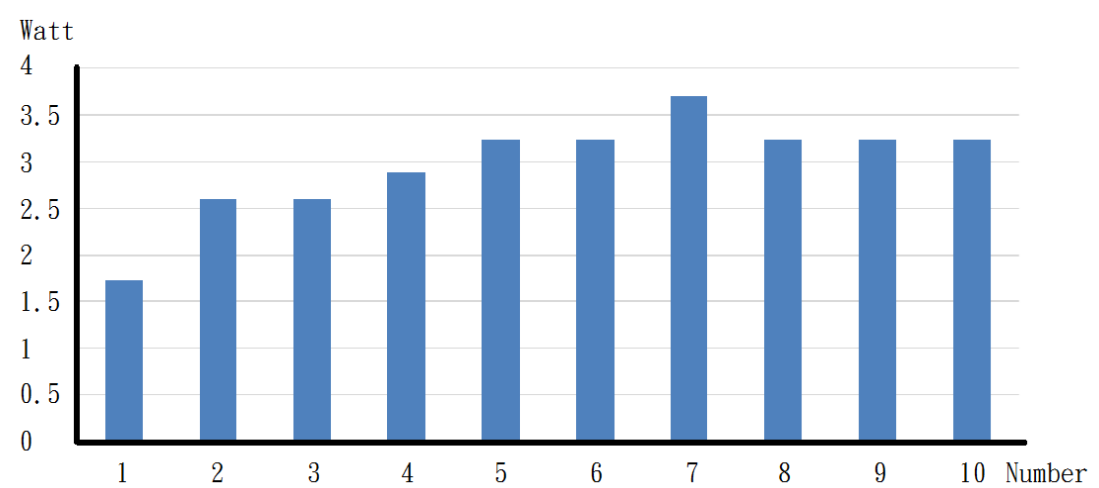

Figure 24. Power of Type-5 robots

\section{Conclusions}

In short, the measurement results can be used to demonstrate the performance of a robot as shown in table 2 :

1. The energy consumption of the Type- 1 robot is the maximum, and that of the Type- 2 robot is the minimum.

2. The Type- 2 battery's recover is the maximum, and that of Type- 1 is the minimum.

3. The power of the Type- 5 robot is the maximum, and that of the Type- 2 robot is the minimum.

4. The Type-3 robot is the lightest, and the Type-5 robot is the heaviest.

5. A higher energy does not guarantee a higher power.

6. Weight is not an important factor in energy consumption; the operating mechanism is a more important factor.

7. Energy consumption of Volt like Battery's recover, so Battery's recover is affected by energy consumption.

8. We can use more battery to intermittent discharge as the battery voltage can be recovered.

Table 2. Type-1 to Type-5 results

\begin{tabular}{|c|c|c|c|c|} 
Robot & Energy Consumption(Volt) & Battery's Volt recove(Volt) & Power(Watt) & Weight(kg) \\
\hline Type-1 & $0.05 \sim 0.1$ & $0 \sim 0.08$ & $0.6 \sim 1.3$ & 1.6 \\
\hline Type-2 & $0.11 \sim 0.33$ & $0.15 \sim 0.31$ & $0.28 \sim 0.47$ & 1.5 \\
\hline Type-3 & $0.12 \sim 0.16$ & $0.12 \sim 0.2$ & $0.4 \sim 0.69$ & 1.15 \\
\hline Type-4 & $0.08 \sim 0.17$ & $0.09 \sim 0.26$ & $1.14 \sim 1.76$ & 3.7 \\
\hline Type-5 & $0.06 \sim 0.14$ & $0.06 \sim 0.13$ & $1.73 \sim 3.7$ & 4.2 \\
\hline
\end{tabular}

\section{References}

1. Guardabrazo, T.A. and Gonzalez de Santos P, Industrial Robot: An International Journal, Building an energetic model to evaluate and optimize power consumption in walking robots, 31(2), 201-208 (2004)

2. Lin, S.-J, On discharging modeling and capacity estimation of Li-Ion battery, Master Program of Electrical and Control Engineering (2005)

3. YUASA, Valve regulated lead-acid batteries short form brochure (2006)

4. Wong, Y.-T, Real-Time terrain adaptation control for quadrupled robot (2012)

5. Bruzzone, L. and Fanghella, P. Industrial Robot: An International Journal, Mantis: hybrid legwheel ground mobile robot, 41 (1), 26-36 (2014) 